\title{
Adverse drug reactions in older patients: an Italian observational prospective hospital study
}

\author{
This article was published in the following Dove Press journal: \\ Drug, Healthcare and Patient Safety \\ 16 July 2012 \\ Number of times this article has been viewed
}

\section{Anita Conforti ${ }^{1}$ \\ Davide Costantini' \\ Francesca Zanetti ${ }^{2}$ \\ Ugo Moretti' \\ Matteo Grezzana ${ }^{2}$ \\ Roberto Leone' \\ 'Department of Public Health and Community Medicine, Section of Pharmacology, University of Verona, Verona, Italy; ${ }^{2}$ Third Division of Geriatrics, Verona University Hospital, Verona, Italy}

Correspondence: R Leone Pharmacology Unit, University Hospital "GB Rossi", ple LA Scuro I0,

37 I 34 Verona, Italy

Tel +390458027602

Fax +390458124876

Email roberto.leone@univr.it
Background: In adults over 65 years of age, the frequency of adverse drug reaction (ADRs) related hospital admissions is higher than in younger adults, and the frequency of ADRs occurring during hospital stay highly ranges. The review was designed to evaluate the frequency of ADRs, both resulting in hospital admission and occurring during the hospital stay of older patients, while identifying the types of reactions and the associated drugs.

Methods: Age, sex, date, and diagnosis of admission of all patients aged 65 and over admitted in three geriatric wards of University Hospital of Verona, Italy, from February to July 2009 were registered by nurses on a special form. In the specific cases of admissions caused by an ADR as well as in the cases of an ADR occurring during the hospital stay, the type of reactions and the suspected drugs were also registered by nurses and physicians involved in the study.

Results: During the six months of the study, 1023 patients matched the inclusion criteria and were included in the study. One hundred fourteen hospital admissions $(11.1 \%)$ were caused by ADRs, while 256 patients $(25.0 \%)$ had an ADR during their hospital stay. The duration of hospital stay was significantly longer in patients who developed an ADR during their time in hospital, 18.7 (95\% CI: 17.2-20.1) days versus 12.6 (95\% CI: 11.9-13.3) days. Electrolyte disorders, gastrointestinal disorders, anemia, and International Normalized Ratio increase were the more frequent observed ADRs, with diuretics, antithrombotic agents, and antibacterials as the main involved drugs. Our study confirms that ADRs are an important cause of hospitalization in older patients. In addition, the frequency of ADRs occurring during hospital stay is high and causes prolonged hospitalization.

Keywords: adverse drug reaction, anemia, electrolyte disorders, hospital admission, hospital stay, older patients, gastrointestinal disorders

\section{Introduction}

Physiological and pathological changes observed in older people appear to affect the mechanism of action of drugs and the function of the various structures involved. In older people we find upgrading and alterations in the number of receptors, changes in signal transduction (function of second messengers), and differences in intracellular response. Renal and hepatic functions can be altered as well, with consequences found for the pharmacokinetics of administered drugs. This may explain why in older people there is sometimes a greater sensitivity to the effects of certain drugs and sometimes a diminished response to therapy. Regimens that are safe for other age groups may be inappropriate for geriatric patients. ${ }^{1}$ Moreover, older patients often use multiple drugs: it has been calculated that about $80 \%$ of patients over 65 years of age take medications and that about $40 \%$ are taking five or more drugs regularly. ${ }^{2,3}$ 
As the benefits of medications are always accompanied by harmful effects, it is not surprising that older people are at increased risk of developing adverse drug reactions (ADRs). Several studies have been conducted on ADRs as a cause of admission to hospital in the older population, ${ }^{4-7}$ and in a meta-analysis of observational studies, the percentage of ADR-related hospital admissions was reported to be four times higher in older than in younger patients $(16.6 \%$ versus $4.1 \%){ }^{8}$ In a recent systematic review of 25 studies of hospital admissions associated with ADRs, the admission rate for older patients was $10.7 \%$, much higher than for adults in general $(6.3 \%)$ or for children $(4.1 \%) .{ }^{9}$ Fewer studies have focused on ADRs occurring in older patients during their stay in hospital, reporting a prevalence of ADRs ranging from $13.6 \%$ to $46.2 \% .^{10-13}$

We conducted an observational prospective study that aimed to calculate the frequency of adverse drug reactions in older patients, both ADRs causing hospital admission and those occurring during patients' stay in hospital, and to describe the types of reactions and associated drugs. The study also had the educational objective of encouraging health care providers to report ADRs to the national pharmacovigilance system and of facilitating collaboration between medical and nursing staff.

\section{Methods}

\section{Patients and data collection}

The study was carried out in three geriatric wards ( 97 beds) of the Verona University Hospital in northern Italy. All patients aged 65 years and over who were admitted to these wards between February and July 2009 were included. Patients coming from, or transferred within 24 hours to, other hospital wards were excluded from the study.

Each patient's age and sex, the date, and their diagnosis at admission were registered by nurses on a special form. During their time in hospital, patients were monitored for the occurrence of drug-related problems. In the case of admissions due to an ADR, or of an ADR occurring during hospital stay, the type of reactions and the suspected drugs were registered by nurses and physicians involved in the study. At each patient discharge the completed form was discussed and validated by physicians.

\section{Data analysis}

An ADR was defined as an appreciably harmful or unpleasant reaction, resulting from an intervention related to the use of a medicinal product, which predicts hazard from future administration, and which warrants prevention or specific treatment, or alteration of the dosage regimen, or withdrawal of the product. ${ }^{14}$ Reactions were classified following the World Health Organization Adverse Reaction Terminology (WHO-ART). According to the WHO classification of the severity of ADRs, any reaction leading to hospitalization was considered serious, while the severity classification of reactions occurring during patients' stay in hospital was carried out by physicians case by case, on the basis of the patient's symptoms and the cited WHO criteria. ${ }^{15}$

Nurses and physicians involved in the study were invited to report ADRs to the national pharmacovigilance system, in accordance with Italian law.

Means, percentages, and their 95\% confidence intervals ( $95 \% \mathrm{CI})$ were used to compare the characteristics of patients and length of hospital stay in the three groups of patients (without ADR, with ADR as cause of hospitalization, and with ADR during hospitalization).

\section{Results}

During the 6 months of the study, 1215 patients were hospitalized in the three geriatrics departments. Of these patients, 1023 (84\%) matched the inclusion criteria and were included in the study. The patients' mean age was 81.9 (95\% CI: 81.5-82.3) years. The women's mean age (83.0, 95\% CI: 82.4-83.6) proved significantly higher than the men's (80.7, 95\% CI: 80.1-81.3), in line with the composition of the Italian population. The age of patients with ADRs (82.4, 95\% CI: 81.7-83.1) was not statistically different from that of patients without ADRs (81.6, 95\% CI: 81.0-82.2).

Table 1 shows the frequency of patients without and with ADRs, and the duration of their stay in hospital. Altogether a total of 370 patients developed an ADR; for 114 of them the reactions were the cause of hospital admission, while for 256 patients ADRs occurred during hospital stay. The frequency of admissions caused by an ADR was higher in women than in men, although the difference was not significant. The frequency of women who had ADRs during hospital stay was also higher than that of men, but again the difference was not significant. As shown in Table 1, the duration of hospital stay was longer in patients who developed an ADR during their time in hospital, whether male or female.

The rate of hospital admissions was constant during the first four months of the study, with a decrease in the last 2 months that corresponded with the general decrease in the number of hospital admissions in summer. The monthly number of patients hospitalized because of ADR and of those who had an ADR during their stay in hospital was also relatively constant. 
Table I Patients and length of hospitalization, subdivided according to ADR appearance and sex

\begin{tabular}{|c|c|c|c|}
\hline & $\begin{array}{l}\text { All } \\
(n=1023)\end{array}$ & $\begin{array}{l}\text { Women } \\
(n=520)\end{array}$ & $\begin{array}{l}\text { Men } \\
(n=503)\end{array}$ \\
\hline Patients without ADR $(\%[95 \% \mathrm{Cl}])$ & $65.4(60.9-66.7)$ & $63.1(58.9-67.2)$ & $67.8(63.7-71.9)$ \\
\hline Days of hospital stay, mean $(95 \% \mathrm{Cl})$ & $12.6(11.9-13.3)$ & $12.6(\mid 1.5-13.7)$ & $12.6(\mid 1.6-13.6)$ \\
\hline Patients with ADR as cause of hospitalization (\% [95\% Cl]) & II.I (9.2-13.0) & $12.1(9.3-14.9)$ & $10.1(7.5-12.8)$ \\
\hline Days of hospital stay, mean $(95 \% \mathrm{Cl})$ & $13.6(11.9-15.3)$ & $15.2(12.6-17.8)$ & $11.5(9.6-13.4)$ \\
\hline Patients with ADR during hospitalization (\% [95\% Cl]) & $25.0(22.4-27.7)$ & $27.1(23.3-30.9)$ & $22.9(19.2-26.5)$ \\
\hline Days of hospital stay, mean $(95 \% \mathrm{Cl})$ & I8.7 (I7.2-20.1) & $18.7(16.8-20.6)$ & $18.7(16.5-20.9)$ \\
\hline
\end{tabular}

Abbreviations: $\mathrm{ADR}$, adverse drug reaction; $\mathrm{Cl}$, confidence interval; $\mathrm{n}$, number.

Table 2 shows the main ADRs and related drugs which caused hospital admission. Electrolyte disorders were the most frequently observed ADRs; among this group of reactions hyponatremia was the most common, followed by hypokalemia and hyperkalemia. Potassium-sparing diuretics, anti-ulcers, and angiotensin-converting-enzyme (ACE) inhibitors were the drugs most often associated with electrolyte disorders. On the whole, 84 drugs were responsible for hospital admission, of which the most frequently involved

Table 2 ADRs causing hospital admission, grouped to the System Organ Classification of WHO-ART, and related drugs

\begin{tabular}{|c|c|}
\hline ADRs & Drug classes* \\
\hline \multicolumn{2}{|c|}{ Metabolic and nutritional disorders (4I) } \\
\hline Hyponatremia (2I) & $\begin{array}{l}\text { Potassium-sparing diuretics ( } 13) \text {; } \\
\text { antiulcer drugs ( } 8 \text { ); ACE inhibitors (3); } \\
\text { antidepressants (3); diuretics (3); angiotensin-2 } \\
\text { receptor antagonists (2) }\end{array}$ \\
\hline Hypokalemia (9) & Diuretics (5); ACE inhibitors (2) \\
\hline Hyperkalemia (8) & ACE inhibitors (6); potassium-sparing diuretics (4) \\
\hline Hypoglycemia (4) & Hypoglycemic agents (4) \\
\hline Dehydration (4) & Diuretics (3) \\
\hline \multicolumn{2}{|c|}{ Red blood cell disorders (16) } \\
\hline Anemia (14) & $\begin{array}{l}\text { Antithrombotic agents (6); analgesics } \\
\text { and antipyretics (5); antitumorals (4); } \\
\text { corticosteroids (2) }\end{array}$ \\
\hline \multicolumn{2}{|c|}{ Body as a whole/general disorders (16) } \\
\hline Syncope (9) & $\begin{array}{l}\text { ACE inhibitors (4); diuretics (2); beta-blockers (2); } \\
\text { calcium channel blockers ( } 2 \text { ) }\end{array}$ \\
\hline \multicolumn{2}{|c|}{ Gastrointestinal system disorders (15) } \\
\hline Diarrhea (5) & Antibacterials (5) \\
\hline Vomiting (3) & Antibacterials (2) \\
\hline \multicolumn{2}{|c|}{ Platelet, bleeding and clotting disorders (1 2) } \\
\hline INR increase (10) & Antithrombotic agents $(10)$ \\
\hline \multicolumn{2}{|c|}{ Urinary system disorders (I I) } \\
\hline Renal failure (6) & $\begin{array}{l}\text { Antibacterials (5); ACE inhibitors (3); potassium- } \\
\text { sparing diuretics ( } 2 \text { ) }\end{array}$ \\
\hline \multicolumn{2}{|c|}{ Psychiatric disorders (10) } \\
\hline Confusion (5) & Antidepressants (2); antipsychotics (2) \\
\hline \multicolumn{2}{|c|}{$\begin{array}{l}\text { Notes: Groups of ADRs that occurred in at least } 10 \text { patients are shown. *Drug } \\
\text { classes suspected in at least two patients are listed. Figures in parentheses indicate } \\
\text { the number of patients. } \\
\text { Abbreviations: ACE, angiotensin converting enzyme; ADRs, adverse drug reac- } \\
\text { tions; INR, international normalized ratio; WHO-ART, World Health Organization } \\
\text { Adverse Reaction Terminology. }\end{array}$} \\
\hline
\end{tabular}

were diuretics, antithrombotic agents (anticoagulants and antiplatelets), and ACE inhibitors.

Among the 60 different ADR diagnoses issued during patients' time in hospital, electrolyte disorders were again the most frequently reported, although in a different order to that of adverse drug reactions leading to hospitalization (Table 3 ). Other systemic ADRs frequently observed were anemia, increase of International Normalized Ratio (INR), diarrhea, and rash. More than half of the ADRs (53.5\%) that occurred during hospital stay were classified by physicians as serious. Altogether, 73 different drugs were considered responsible for ADRs. The most frequently involved classes of drugs were diuretics, antithrombotic agents, and antibacterials. Furosemide (83 cases), enoxaparin (31 cases), warfarin (17 cases), and ampicillin plus sulbactam (16 cases) were the drugs most frequently associated with ADRs in hospitalized patients.

During the 6 months of the study, 32 reports of ADRs were sent to the Italian pharmacovigilance system. Of these, $20(87.5 \%)$ reported a serious ADR. A total of $72 \%$ of reports were sent by physicians, the others by nurses. These reports represented only $14 \%$ of the ADRs causing hospital admission and $6.2 \%$ of those occurring during hospital stay in patients included in the study.

\section{Discussion}

Our data show that $11.1 \%$ of admissions to three geriatric departments of the University Hospital of Verona were related to ADRs. This percentage is the same as that found in the systematic review by Kongkaev et $\mathrm{al}^{9}$ and is slightly lower than that found in the meta-analysis by Beijer and de Blaey. ${ }^{8}$ On the other hand, the number of drug-related admissions reported in the present study is significantly higher than that found by other researchers in our country. ADRs were considered to be the cause of hospitalization in $3.8 \%$ of all admissions in a multicenter pharmacoepidemiology survey conducted in Italy between 1988 and 1997, involving more than 28,000 older patients. ${ }^{5}$ Moreover, in a more recent Italian prospective analysis of 1756 medical records of older patients, the 
Table 3 ADRs during hospital stay, grouped according to the System Organ Classification of WHO-ART, and related drugs

\begin{tabular}{|c|c|}
\hline ADRs & Drug classes* \\
\hline \multicolumn{2}{|c|}{ Metabolic and nutritional disorders (I I 0$)$} \\
\hline Hypokalemia (75) & $\begin{array}{l}\text { Diuretics (73); antithrombotic agents (8); } \\
\text { Potassium-sparing diuretics (3); cardiac } \\
\text { glycosides (3) }\end{array}$ \\
\hline Hyponatremia (17) & $\begin{array}{l}\text { Potassium-sparing diuretics (I2); } \\
\text { diuretics (6); antiulcer agents (4) }\end{array}$ \\
\hline Hyperglycemia (I3) & Corticosteroids (13) \\
\hline Hyperkalemia (I2) & $\begin{array}{l}\text { Potassium-sparing diuretics (8); } \\
\text { corticosteroids (2); antiulcer agents (2); } \\
\text { antithrombotic agents (2); angiotensin-2 } \\
\text { receptor antagonists (2) }\end{array}$ \\
\hline \multicolumn{2}{|c|}{ Gastrointestinal system disorders (34) } \\
\hline Diarrhea (I5) & $\begin{array}{l}\text { Antibacterials (14); antithrombotic } \\
\text { agents (2) }\end{array}$ \\
\hline Constipation (10) & $\begin{array}{l}\text { Analgesics and antipyretics (6); } \\
\text { opioids (4) }\end{array}$ \\
\hline \multicolumn{2}{|c|}{ Platelet, bleeding and clotting disorders (3I) } \\
\hline INR increase (15) & Antithrombotic agents (I5); diuretics (3) \\
\hline Thrombocytopenia (13) & Antithrombotic agents (13); diuretics (2) \\
\hline \multicolumn{2}{|c|}{ Skin and appendages disorders ( $3 \mathrm{I}$ ) } \\
\hline Rash erythematosus (I5) & $\begin{array}{l}\text { Antibacterials (14); antithrombotic } \\
\text { agents (2); diuretics (2) }\end{array}$ \\
\hline Urticaria (5) & Antibacterials (2) \\
\hline Hyperhidrosis (2) & Opioids (2) \\
\hline \multicolumn{2}{|c|}{ Application site disorders (20) } \\
\hline $\begin{array}{l}\text { Hematoma at the } \\
\text { injection site (18) }\end{array}$ & $\begin{array}{l}\text { Antithrombotic agents (17); analgesic/ } \\
\text { antipyretics (2); NSAIDs (2) }\end{array}$ \\
\hline \multicolumn{2}{|c|}{ Red blood cell disorders (19) } \\
\hline Anemia (19) & $\begin{array}{l}\text { Antithrombotic agents (17); analgesics and } \\
\text { antipyretics (8); diuretics (3) }\end{array}$ \\
\hline
\end{tabular}

Notes: Groups of ADRs that occurred in at least 10 patients are shown. *Drug classes suspected in at least 2 patients are listed. Figures in parentheses indicate the number of patients.

Abbreviations: ADRs, adverse drug reactions; INR, international normalized ratio; NSAIDs, nonsteroidal anti-inflammatory drugs; WHO-ART, World Health Organization Adverse Reaction Terminology.

proportion of drug-related admission was $5.8 \% .{ }^{6}$ It should be emphasized that in our study the mean age $( \pm \mathrm{SD})$ of patients was $81.9 \pm 7.1$ years, while in earlier Italian studies patients were younger. For instance, in the study by Franceschi et al, ${ }^{6}$ the average age of hospitalized patients was $76.5 \pm 7.4$ years, significantly different from our data ( $t$-test, $P<0.01)$. It is known that with increasing age, patients become more frail and take more drugs, both of which lead to a higher risk of $\mathrm{ADR}^{2,3}$ It is also worth recalling that some recent studies showed that ADR-related hospital admissions of older people have increased over the last decades, so close attention to this problem is warranted. ${ }^{16,17}$

In the present study, the percentage of ADRs in patients during their hospital stay was $25 \%$, in line with previous studies of older patients. ${ }^{10-13}$ Recently a large prospective study among UK hospital in-patients with an average age of
63 years suggested that at least 1 in 7 inpatient episodes are complicated by an adverse drug reaction. ${ }^{18}$ The widely differing estimates of ADR percentage in various studies may be explained by differences in data collection methods, in definitions of ADR, characteristics of patients, typology of wards involved, and duration of hospital stay. In our study the occurrence of an ADR during hospital stay increased the median length of that stay by $50 \%$, in line with the literature. ${ }^{12,13,18,19}$

In this study, the mean age of patients with ADRs did not differ from the age of patients without ADRs, in contrast with reports by other researchers of a higher median age in ADR patients than in non-ADR groups. ${ }^{18,20}$ This may be due to the fact that our data come from a geriatric setting and the mean age of all patients included was very high. The slightly higher percentage of ADRs in women compared to men found in our study concurs with previous findings that female sex is a risk factor for the development of ADRs. ${ }^{21}$ Some studies have also documented that women are at higher risk than men of hospitalization because of an ADR, ${ }^{5,20}$ although other investigations were not able to confirm this finding., ${ }^{4,7}$ Known reasons for sex-related vulnerability to ADRs include differences in pharmacokinetics leading to possible under or over-exposure to drugs in women, as well as differences in the pattern of drug use. Female sex has been associated with polypharmacy in elderly people as well..$^{22,23}$

Alterations in sodium and potassium blood levels, blood disorders including anemia and international normalized ratio (INR) increase, gastrointestinal disorders, and syncope were the reactions most frequently involved in drug-related hospital admissions. This is quite consistent with data found in the prospective study by Olivier et al, ${ }^{7}$ where hematological complaints (26\%), metabolic (20\%) and neurological disorders $(18 \%)$, and cardiovascular problems (17\%) represented the most common ADRs leading to hospitalization. On the other hand, in the study by Franceschi et $\mathrm{al}^{6}$ gastrointestinal disorders (mainly bleeding and peptic ulcer related to nonsteroidal anti-inflammatory drug use) accounted for nearly one half of ADR-related hospitalizations ( $47 \%$ versus $12 \%$ in our study), followed by disorders of the hematopoietic (20\%) and cardiovascular (13\%) systems. Again, the difference in age between the two study populations may in part explain these differences. It is also to be noted that, in Italy in recent years, upper-gastrointestinal bleeding has been more and more frequently treated by endoscopy, and patients are not usually admitted to hospital for this procedure. ${ }^{24}$

In older outpatients, electrolyte abnormalities are quite common and can relate to many factors such as frequency and 
dose of drug therapy, concurrent assumption of incompatible salts, failure to replace a needed electrolyte, hydration state, and inadequate monitoring. Prescription of diuretics in UK primary care has been associated with a high frequency of hyponatremia and hypokalemia. ${ }^{25}$ The researchers showed that hyponatremia was significantly associated with increased age: the odds ratio for developing hyponatremia in patients over the age of 70 years was 3.87 compared with those of $\leq 70$ years. It is now known that hyponatremia can occur several days or months after the initiation of proton pump inhibitors, although these drugs were initially overlooked as a cause of hyponatremia. A case of hyponatremic delirium leading to rhabdomyolysis has also been reported. ${ }^{26}$ It is well known that potassium level alterations are responsible for conduction disturbances, dangerous arrhythmias, cardiogenic syncope, and sudden cardiac death. Hyperkalemia may develop as a complication of therapy with ACE inhibitors or angiotensin-2 receptor blockers in elderly patients with common associated risk factors that interfere with renal excretion of potassium, such as advanced age, female sex, reduced renal functional reserve, and decreased renal perfusion. ${ }^{27,28}$ As a consequence, especially frail older patients at high risk of electrolyte imbalance should be monitored closely by general practitioners to avoid acute life-threatening cardiac events. Hospital admission caused by INR increase in warfarin-treated patients and renal failure related to drugs could probably be avoided, especially with close monitoring of patients during therapy.

Electrolyte disturbances associated with cardiovascular and antiulcer drugs were also the ADRs most frequently observed during hospital stay. This finding is in agreement with the study by Passarelli et al who identified hypokalemia associated with diuretics as the most prevalent ADR in an older hospitalized population. ${ }^{13}$ In the analysis by Davies et al, electrolyte disturbances associated with loop diuretics were the most frequently occurring ADR, ${ }^{18}$ which is in line with our data. The relatively high number of ADRs caused by application-site disorders in the present study probably relates to the involvement of nurses in the project, and shows how they can cooperate with physicians in detecting and reporting ADRs. Good communication among health care providers is pivotal to the development of an effective therapeutic partnership with the patient, and can improve patients' drug adherence.

The use of inappropriate drugs is widely recognized as one of the major factors influencing the risk of ADRs in older patients, along with the lack of patient monitoring during hospitalization. ${ }^{1,29}$ The review of 17 articles by Howard et al shows that about $50 \%$ of ADRs that caused hospital admission were preventable. ${ }^{30}$ Even with regard to ADRs during hospital stay, the literature shows that a high percentage could have been avoided. ${ }^{18}$ Our study did not focus on inappropriate medications, but most drug-related electrolyte disturbances detected as causing or occurring during hospitalization could be avoided by close monitoring of patients with simple, routine blood tests.

The low number of ADR reports sent to the national pharmacovigilance system by physicians and nurses, despite their involvement in the study, is indicative of the poor adherence of Italian health care providers to pharmacovigilance.

In conclusion, our study confirms that ADRs are an important cause of hospitalization in older patients. In addition, the percentage of ADRs occurring during hospital stay is high and causes prolonged hospitalization, with a significant impact on health care costs.

\section{Acknowledgment}

The authors regret to announce the passing of Dr Davide Costantini on 7 April, 2012.

\section{Disclosure}

The authors report no conflicts of interest in this work.

\section{References}

1. Onder G, Landi F, Liperoti R, Fialova D, Gambassi G, Bernabei R. Impact of inappropriate drug use among hospitalized older adults. Eur J Clin Pharmacol. 2005;61(5-6):453-459.

2. Repetto L, Audisio RA. Elderly patients have become the leading drug consumers: it's high time to properly evaluate new drugs within the real targeted population. $J$ Clin Oncology. 2006;24(35): e62-e63.

3. Nguyen JK, Fouts MM, Kotabe SE, Lo E. Polypharmacy as a risk factor for adverse drug reactions in geriatric nursing home residents. Am J Geriatr Pharmacother. 2006;4(1):36-41.

4. Mannesse CK, Derkx FH, de Ridder MA, Man in 't Veld AJ, van der Cammen TJ. Contribution of adverse drug reactions to hospital admission of older patients. Age Ageing. 2000;29(1):35-39.

5. Onder G, Pedone C, Landi F, et al. Adverse drug reactions as cause of hospital admissions: results from the Italian Group of Pharmacoepidemiology in the Elderly (GIFA). JAm Geriatr Soc. 2002;50(12): 1962-1968.

6. Franceschi M, Scarcelli C, Niro V, et al. Prevalence, clinical features and avoidability of adverse drug reactions as cause of admission to a geriatric unit: a prospective study of 1756 patients. Drug Saf. 2008;31(6):545-556.

7. Olivier P, Bertrand L, Tubery M, Lauque D, Montastruc JL, Lapeyre-Mestre M. Hospitalizations because of adverse drug reactions in elderly patients admitted through the emergency department: a prospective survey. Drugs Aging. 2009;26(6):475-482.

8. Beijer HJ, de Blaey CJ. Hospitalisations caused by adverse drug reactions (ADR): a meta-analysis of observational studies. Pharm World Sci. 2002;24(2):46-54.

9. Kongkaev C, Noyce PR, Ashcroft DM. Hospital admissions associated with adverse drug reactions: a systematic review of prospective observational studies. Ann Pharmacother. 2008;42(7):1017-1025.

10. Sánchez Muñoz-Torrero JF, Barquilla P, Velasco R, et al. Adverse drug reactions in internal medicine units and associated risk factors. Eur $J$ Clin Pharmacol. 2010;66(12):1257-1264. 
11. Leach S, Roy SS. Adverse drug reactions: an investigation on an acute geriatric ward. Age Ageing. 1986;15(4):241-246.

12. Cecile M, Seux V, Pauly V, et al. Adverse drug events in hospitalized elderly patients in a geriatric medicine unit: study of prevalence and risk factors. Rev Med Interne. 2009;30(5):393-400.

13. Passarelli MC, Jacob-Filho W, Figueiras A. Adverse drug reactions in an elderly hospitalised population: inappropriate prescription is a leading cause. Drugs Aging. 2005;22(9):767-777.

14. Edwards IR, Aronson JK. Adverse drug reactions: definitions, diagnosis, and management. Lancet. 2000;356(9237):1255-1259.

15. The Uppsala Monitoring Centre, WHO Collaborating Centre for International Drug Monitoring. Glossary of terms used in Pharacovigilance. In: Practical Pharmacovigilance. Uppsala: UMC; 2011. Available from: http://www.who-umc.org/graphics/25301.pdf. Accessed 5 March, 2012.

16. Zhang M, Holman CD, Preen DB, Brameld K. Repeat adverse drug reactions causing hospitalization in older Australians: a populationbased longitudinal study 1980-2003. Br J Clin Pharmacol. 2007;63(2): 163-170.

17. Hartholt KA, van der Velde N, Looman CW, et al. Adverse drug reactions related hospital admissions in persons aged 60 years and over, The Netherlands, 1981-2007: less rapid increase, different drugs. PLoS One. 2010;5(11):e13977.

18. Davies EC, Green CF, Taylor S, Williamson PR, Mottram DR, Pirmohamed M. Adverse drug reactions in hospital in-patients: a prospective analysis of 3695 patient-episodes. PLoS One. 2009;4(2):e4439.

19. Ramirez E, Carcas AJ, Borobia AM, et al. A pharmacovigilance program from laboratory signals for the detection and reporting of serious adverse drug reactions in hospitalized patients. Clin Pharmacol Ther. 2010;87(1):74-86.

20. Pirmohamed M, James S, Meakin S, et al. Adverse drug reactions as cause of admission to hospital: prospective analysis of 18820 patients. BMJ. 2004;329(7456):15-19.
21. Davies EC, Green CF, Mottram DR, Pirmohamed M. Adverse drug reactions in hospitals: a narrative review. Curr Drug Saf. 2007;2(1): $79-87$.

22. Jyrkkä J, Enlund H, Korhonen MJ, Sulkava R, Hartikainen S. Patterns of drug use and factors associated with polypharmacy and excessive polypharmacy in elderly persons: results of the Kuopio 75+ study: a cross-sectional analysis. Drugs Aging. 2009;26(6):493-503.

23. Pokela N, Bell JS, Lihavainen K, Sulkava R, Hartikainen S. Analgesic use among community-dwelling people aged 75 years and older: a population-based interview study. Am J Geriatr Pharmacother. 2010;8(3):233-244.

24. Loperfido S, Baldo V, Piovesana E, et al. Changing trends in acute upper-GI bleeding: a population-based study. Gastrointest Endosc. 2009;70(2):212-224.

25. Clayton JA, Rodgers S, Blakey J, Avery A, Hall IP. Thiazide diuretic prescription and electrolyte abnormalities in primary care. $\mathrm{Br} J$ Clin Pharmacol. 2006;61(1):87-95.

26. Bebarta VS, King JA, McDonough M. Proton pump inhibitor-induced rhabdomyolysis and hyponatremic delirium. Am J Emerg Med. 2008;26(4):519. e1-e2.

27. Giancaspro G, Suppa M, Genuini I, Caselli S, Fedele F. Syncope caused by iatrogenic hyperkalemia. $J$ Cardiovasc Med (Hagerstown). 2009;10(1):72-74.

28. Palmer BF. Managing hyperkalemia caused by inhibitors of the rennin-angiotensin-aldosterone system. $N$ Engl J Med. 2004;351(6): 585-592.

29. Corsonello A, Pranno L, Garasto S, Fabietti P, Bustacchini S, Lattanzio F. Potentially inappropriate medication in elderly hospitalized patients. Drugs Aging. 2009;26(Suppl 1):31-39.

30. Howard RL, Avery AJ, Slavenburg S, et al. Which drugs cause preventable admissions to hospital? A systematic review. Br J Clin Pharmacol. 2007;63(2):136-147.
Drug, Healthcare and Patient Safety

\section{Publish your work in this journal}

Drug, Healthcare and Patient Safety is an international, peer-reviewed open-access journal exploring patient safety issues in the healthcare continuum from diagnostic and screening interventions through to treatment, drug therapy and surgery. The journal is characterized by the rapid reporting of reviews, original research, clinical, epidemiological and

\section{Dovepress}

post-marketing surveillance studies, risk management, health literacy and educational programs across all areas of healthcare delivery. The manuscript management system is completely online and includes a very quick and fair peer-review system. Visit http://www.dovepress.com/ testimonials.php to read real quotes from published authors. 